\title{
Does Governance Affect Organizational Performance? Governance Structure and Hospital Performance in Tennessee
}

\author{
Chul-Young Roh* and M. Jae Moon**
}

\begin{abstract}
It is critical for a hospital to perform efficiently, to provide quality health care, and to maintain a high reputation in the community that the hospital serves. Since hospital governing boards are charged with ensuring superior performance on the part of the hospital, it is important to understand the features of governing boards that contribute positively to hospital performance. This study investigates the relationship between hospital governance and hospital performance in Tennessee. It measures the performance of 125 community hospitals from 2008 to 2012 using data envelopment analysis (DEA). This study finds that hospitals that adopt a corporate governance model perform better than hospitals that embrace a philanthropic one.
\end{abstract}

Keywords: measurement of efficiency, data envelopment analysis (DEA), hospital governance

\section{INTRODUCTION}

Hospital governing boards are critical in influencing the performance of hospitals and are a crucial component of health care delivery in the United States. Governance is defined as the process of overseeing the functions and performance of an organization by defining the organization's mission, values, and vision through laws, norms, power, or language (Bevir, 2013). It encompasses accountability and responsibility for the overall management of the organization. Specifically, health care governance could be considered a process of senior-level leadership and decision-making by a board of directors, CEO, senior managers, and clinical leaders.

\footnotetext{
* Chul-Young Roh is an associate professor in the Department of Health Sciences at Lehman College/CUNY. E-mail: chulyung.roh@lehman.cuny.edu.

** M. Jae Moon is Underwood Distinguished Professor in the Department of Public Administration at Yonsei University, Seoul, Korea. E-mail: mjaemoon@gmail.com.
}

Manuscript received May 30, 2016; out for review June 15, 2016; review completed July 25, 2016; accepted August 5, 2016.

The Korean Journal of Policy Studies, Vol. 31, No. 2 (2016), pp. 23-40.

(C) 2016 by the GSPA, Seoul National University 
Most hospitals have their own governing board, which is the axis of hospital governance (Eeckloo, Van Herck, Van Hulle, \& Vleugels, 2004). The governing board is charged with the responsibility of developing both strategic plans and short-term policies, motivating departments to meet their targeted managerial and clinical goals and evaluating their performance, and serving internal and external stakeholders (Taylor, 2000). The way a governing board is run and how it is structured affects how effectively it functions. Some studies (Young, Beekun, \& Ginn, 1992; Alexander, Zuckerman, \& Pointer, 1995; Buchner, 2012; Prybil, 2006; Gu, Langabeer, \& Helton, 2010) have examined the relationship between hospital performance and the characteristics of hospital governing boards, focusing on such factors as board size, board composition, clinical staff participation in governing boards, types of board leadership, and board diversity.

Given the escalating competition among hospitals and the demand to ensure the best use of limited resources, it is critical to explore the relationship between hospital performance and its governance. In this study, performance refers to the conversion of inputs into outputs relative to best practice. In a perfect performance, there would be zero loss of inputs in producing a given quantity of output. A decision-making unit (DMU) operating at best practice level is $100 \%$, efficient, which is indicated by 1 . This study examines the relationship between the overall performance of community hospitals in Tennessee and hospital governance. Community hospitals occupy a unique position in providing health care services in vulnerable economic environments, and community hospitals in Tennessee encompass a wide range of different characteristics ranging across hospital ownership, hospital size, location, and network participation and so offer a good pool for exploring the relationship between hospital performance and governance types.

In examining the relationship between the performance and governance of community hospitals in Tennessee, this study uses data envelopment analysis (DEA). DEA is appropriate for analysis of the hospital industry, since it provides multiple outputs for multiple inputs, which rarely can capture price information. This study is structured as follows. First, we offer a review of the relevant empirical studies on relationships between hospital performance and its governance and follow it with a description of hospital governance models. The research method section specifies DEA and describes the input and output variables and data sources used in this study. The findings section explores the governance model that influences the performance of community hospitals in Tennessee. The discussion section presents our conclusions and provides suggestions for future research. 


\section{LITERATURE REVIEW}

Previous studies have shown that the performance of hospitals is influenced by the characteristics of their governing boards, including such factors as board size, level of participation of medical staff, CEO duality, and composition and board diversity. Some studies (Kovner, 1990; Lipton \& Lorsch 1992; Jenson, 1993; Bader, 1991) have explored the relationship between the size of the governing board and performance. Smaller governing boards improved performance in areas such as timely decision making and the securing of commitments compared to larger governing boards (Kovner, 1990; Lipton \& Lorsch, 1992). Lipton and Lorsch (1992) found that if the size of the governing board has more than 10 members, then it is more difficult for the opinions of all members to be heard. Jensen (1993) found that smaller governing boards improved hospital performance and that governing boards with more than eight members are less likely to perform effectively, since larger governing boards introduce added coordination costs and free-rider problems among governing board members. Bader (1991) has suggested that the optimal size for a governing board to function effectively is 15 .

Reviewing the health care literature on the question of the ideal size for governing boards, Delbecq and Gill (1988) found that health care leaders believe that smallersized governing board are preferable for the development of strategic plans. The smaller the size of governing board within a system, the greater the possibility that the governing board will remain focused on the hospital and board member roles within it rather than being distracted by organization-specific issues. In his survey of 1,400 German hospitals, Buchner (2012) found that board size has a negative relation to financial performance and suggests the size of a governing board should not exceed a critical threshold, since a larger governing board might be inefficient in decision making.

The composition of governing boards (the proportion of external to internal members) gives a further indication of hospital performance. It indicates the level of independence of the governing board. External governing board members represent shareholders or members of the community, while internal ones include the CEO and senior medical staff. Internal governing board members are more familiar with the dynamics of the organization, while external ones can bring new expertise and change into the organization. Jermias (2007) argues that the independence of governing boards has a negative effect on performance, concluding that the internal governing board members are in a better position than external governing board members to motivate and supervise hospital management. Fama and Jensen (1983) and Jensen (1993), on the other hand, argue that a higher number of external governing board members provides a better forum for decision making and has a positive influence on performance. Conger, 
Lawler, and Finegold (2001) found that governing boards whose internal members made up less tan $10 \%$ of the total number of members were able to develop external relationships and internal strategic roles more effectively than boards composed of a higher percentage of internal members.

Medical staff members are asked to join governing boards to provide expertise regarding health care services and delivery issues. Medical staff participation on a governing board can enhance the performance of the hospital, especially in the area of clinical performance. Alexander et al. (1995) argue that medical staff participation in governing boards may reduce the possibility of conflicts arising between the interests of the hospital and those of the professional staff. Medical staff participation on governing boards can provide governing boards with the information needed to enhance the efficiency of the hospital (Young, Beekun, \& Ginn, 1992). In their examination of 131 hospitals, Shortell and LoGerfo (1981) found that medical staff participation on governing boards positively affects hospital performance, primarily in the area of surgical mortality rate. Other studies (Molinari, Morlock, Alexander, \& Lyles, 1993; Goes \& Zhan, 1995) also have found that medical staff involvement on governing boards is the most effective method for improving hospital performance. Prybil (2006) and $\mathrm{Gu}$ et al. (2010) also argue that better-performing hospitals have a higher proportion of medical staff who have a vote on governing boards.

The structure of the governing board is a critical determinant of hospital performance. Some governing boards are chaired by the hospital CEO, while others are not. Molinari et al. (1997) found that CEO participation on governing boards enhanced the financial performance of hospitals, while Fama and Jensen (1983), Sanders and Carpenter (1998) and Brickley, Coles, and Jarrell (1997) found that CEO duality reduced the CEO's effectiveness in monitoring top management. Board diversity is shaped by the gender, ethnicity, age, religion, occupation, education, and so forth of board members, variables that can affect decision making (Carter, Simkins, \& Simpson, 2003). The degree of diversity among the members of a governing board, including the percentage of women and minorities, has been identified as a critical factor how well an organization performs. Burke (1997), Singh, Vinnicombe, and Johnson (2001) and Carter et al. (2003) argue that there is a positive relationship between the diversity of a governing board and organizational performance.

\section{HOSPITAL GOVERNANCE MODELS}

Flynn (2002) defines clinical governance as the control process that establishes the functions and measures the performance of an organization by defining the organiza- 
tion's mission, vision, and values. Governance models help clarify the structure of governing boards and their relationship with internal and external stakeholders (Carver, 1990).

Several governance models have been developed. The policy-driven governance model created by Carver (1990), is premised on the idea that the board of directors is empowered to assume accountability for the organizations that it governs. This governance model can be applied to the governing board of any organization. It is designed to encourage boards to focus on the larger issues, to clearly delegate responsibility, to oversee the work of the management team without meddling, and to strictly evaluate the accomplishments of the organization. The governing board clearly leads its organization.

Pound (1995) focuses on decision-making processes in developing a governance model, theorizing two types of governance models: the managed corporation governance model and the governed corporation model. In the managed corporation governance model, the role of the governing board is to monitor and control management. The governed corporation model, on the other hand, focuses not so much on the competence of management as on the effectiveness of the organization. The decision-making process of the governed corporation model is more robust, pluralistic, and adaptable. This governance model requires a board of directors with expertise and competency to work in an environment that fosters open debate.

Chait, Ryan, and Taylor (2005) define governance as leadership. They have developed three types of governance models: one that emphasizes fiduciary responsibility or stewardship of assets, one that emphasizes collaborating with management to develop a vision for the organization's future, and one that emphasizes cooperation between the board of directors and management to resolve the issues that the organization confronts. The third one, the generative governance model, is more engaging and reflective than the other two. It provides the governing board members, who act as leaders for the organization, with a greater sense of purpose than any other type of governance model.

Charan (2005) has developed a governance model based on the evolutionary process organizations go through. In the first phase, the governing board is ceremonial. The governing board performs its duties in a perfunctory ways. In the second phase, senior managers come to dominate the governing board, and scandals ensue. The governing board is liberated in the third phase; at this point, the board of directors assumes a more active role in governance. In the last phase, the governing board embraces a more cohesive and collective approach to problem solving that adds value to the organization. Charan argues that the type of progressive governance that characterizes the fourth phase leads to better governance through the focus on group dynamics, proper information architecture, and substantive issues that it encourages. 
Using information culled from a consideration of the relationship between governance configuration and a set of hospital performance indicators, Alexander et al. (1988) and Weiner and Alexander (1933) have developed a conceptual model of nonprofit hospital governance that incorporates corporate and philanthropic approaches. The philanthropic governance model tends to be attractive to nonprofit institutions. Out of 54 community hospitals in Tennessee that are follow a philanthropic model, 35 are owned by nonprofit organizations. By the same token, corporate hospital governance is associated with entrepreneurship. Out of 60 hospitals in Tennessee that follow a corporate model, 23 are owned by for-profit hospitals. Nonprofit, for-profit, and public hospitals make an effort to adapt to the current dynamic environments that hospitals confront.

Alexander, Morlock, and Gifford (1988), Weiner and Alexander (1993) and Kim (2007) have compared philanthropic and corporate governance models in terms of board size, heterogeneity, percentage of internal directors, level of CEO participation on governing boards, the extent of the CEO's accountability to governing boards, term limitations, governing board compensation, and strategic activity. Boards that adopt the philanthropic governance model tend to be larger than those that follow the corporate governance model. They also tend to represent broad interests internally as well as externally (Pfeffer, 1972). Boards that follow the corporate governance model are not only relatively smaller in size but also focus on the more traditional functions of organizations (Ewell, 1987). There has been a shift in nonprofit hospitals in recent years from the larger board size of the philanthropic model to the smaller board size of the corporate governance model (Gu et al., 2010).

The degree of heterogeneity of a governing board is assessed by considering members' age, gender, ethnic background, and expertise. Boards that favor the philanthropic model will tend be more heterogeneous than those that embrace the corporate governance model given that the philanthropic governance model places emphasis on addressing a wide range of interests of internal and external stakeholders. Organizations that favor a corporate governance model are more likely to reflect greater homogeneity of expertise (Alexander et al., 1988).

Boards that favor the corporate governance model also tend have a larger number of internal directors than those that favor the philanthropic governance model, and this is because the former focus more on the internal dynamics of their organization than on community relations or outreach programs. Boards that adhere to the corporate governance model tend to achieve greater correspondence between organizational management and policymaking (Mace, 1971). CEOs serve as a bridge between management and the governing board in the organization. CEOs on the governing board play a more critical role in the corporate governance model than the philanthropic governance model, since CEOs in the corporate governance model have more power vis-à-vis the 
governing board. The ability to exercise influence on the governing board is considered critical to improving the linkage between policy making and management, lessening conflict between management and the board of directors, and facilitating appointments to the board of directors that share the same organizational philosophy as the board (Alexander et al., 1988; Johnson, 1986). The duties of the governing board include developing organizational policies and engaging in strategic decision-making, while top management is responsible for carrying out daily operations. In organizations that adopt the corporate governance model, the distinction between strategic decision making and the daily operations of the organization ought in theory to be more clear-cut than in organizations that follow the philanthropic governance model (Mace, 1976), and this distinction between management and the governing board should improve organizational operation and performance through checks and balances (Alexander et al., 1988).

Regarding term service on a governing board, members of boards of directors of organizations that favor the philanthropic model may serve on the board indefinitely and are often allowed to appoint their successors, while boards that follow the corporate governance model restrict the terms of the governing board to prevent the governing board from becoming too conservative and stale (Pfeffer, 1973; Johnson, 1986; Kovner, 1978). In terms of the compensation for governing board services, boards following the philanthropic governance model do not compensate members for their service, while those following the corporate governance model pay the director of the board for his or her services (Alexander et al., Gifford, 1988; Rehm \& Alexander, 1986). In the current health care environment, hospitals whose boards have adopted the corporate governance model are more likely those that have adopted the philanthropic model to be concerned with the competitive position of a hospital (Alexander et al., 1988; Alexander \& Lee, 2006).

\section{RESEARCH METHOD AND DATA}

\section{Research Method: DEA}

To measure the performance of board governance in community hospitals in Tennessee, this study used DEA. DEA is a nonparametric mathematical programming methodology that measures technical efficiency. Here we use data on input and output variables of each hospital to build a piecewise linear surface over the data points. ${ }^{1}$ This

1. Technical and methodological overviews are provided by Seiford and Thrall (1990), Lovell (1993), Ali and Seiford (1993), and Charnes, Cooper, Lewin, and Seiford (1995). 
frontier surface is created by the solution of a sequence of linear programming problems. The degree of technical inefficiency of each hospital, that is, the distance between the observed data and the frontier, is measured as a by-product of the frontier production analysis.

Some benefits of DEA are the following: it does not need to specify a mathematical form for the production function, it reveals relationships that remain obscured in other methodologies, it can handle multiple inputs and outputs, it can be used with any inputoutput measurement, and the sources of inefficiency can be evaluated and measured quantitatively for every evaluated unit (Cook \& Zhu, 2005). Further, DEA is explicitly capable of evaluating the multiproduct nature of hospitals (Rosko, 1990). Due to the characteristics that make DEA powerful, many of studies (Roh, Moon, \& Jung, 2013; Hollingsworth \& Parkin, 1995; Ferrer, Rosko, \& Valmanis, 2006; Linna, Häkkinen, \& Magnussen, 2006) have used DEA to measure hospital performance.

Since being proposed by Farrell (1957) and named by Charnes, Cooper, and Rhodes (1978), DEA has been extended and applied by input and output orientations. The typical DEA can incorporate both the Charnes, Cooper, and Rhodes (CCR) DEA model (Charnes et al., 1978) and the Banker, Charnes, and Cooper (BCC) DEA model (Banker et al., 1984). Charnes et al. (1978) proposed an input-oriented DEA method (CCR DEA model) that measures the efficiency of input to obtain a constant output. In other words, the CCR DEA model presumes the frontier surface in pursuing the maximum possible proportional reduction in input with output held constant for each DMU. This model assumes efficiency for the DMU to be the weighted linear combination of its outputs divided by the weighted linear combination of its inputs, subject to the constraint that the efficiency is between 0 and 1 for each DMU. All weights are restricted to be nonnegative. The linear programming problem that is solved for the $\mathrm{j}$-th hospital in the input-oriented DEA model is as follows:

$$
\begin{aligned}
& \operatorname{Max} \theta=\sum_{m=1}^{M} u_{m} y_{m 0} \\
& \text { s.t. } \sum_{n=1}^{N} v_{n} x_{n 0}=1, \sum_{m=1}^{M} u_{m} y_{m j}-\sum_{n=1}^{N} v_{n} x_{n j} \leq 0, v_{n}, u_{m} \geq 0
\end{aligned}
$$

where

$x_{n}$ is the vector of input quantities for $\mathrm{j}$-th hospital,

$y_{m}$ is the vector of output quantities for $\mathrm{j}$-th hospital,

$v_{n}$ is the vector of the weight of input,

$u_{m}$ is the vector of the weight of output. 
The CCR DEA model is what is known as the constant return to scale (CRS) DEA model, since the resulting technology will be CRS technology. The BCC DEA model, which is the output-oriented DEA model, attempts to seek the maximum proportional increase in output production with input held constant. This model extends the CCR DEA model to account for variable return to scale (VRS) situations. When the decisionmaking units do not all operate at optimal scale, the use of CRS specifications results in measures of technical efficiency that are described by scale efficiencies. Therefore, the BCC DEA model allows us to calculate technical efficiency devoid of these scale efficiencies effects (Coelli, 1996).

The linear programming of the BBC DEA model is as follows:

$$
\begin{aligned}
& \operatorname{Max} \theta=\sum_{m=1}^{M} u_{m} y_{m 0}-\eta_{0} \\
& \text { s.t. } \sum_{n=1}^{N} v_{n} x_{n 0}=1, \sum_{m=1}^{M} u_{m} y_{m j}-\sum_{n=1}^{N} v_{n} x_{n j}-\eta_{0} \leq 0, v_{n}, u_{m} \geq 0
\end{aligned}
$$

where

$x_{n}$ is the vector of input quantities for $\mathrm{j}$-th hospital,

$y_{m}$ is the vector of output quantities for $\mathrm{j}$-th hospital,

$v_{n}$ is the vector of the weight of input,

$u_{m}$ is the vector of the weight of output,

$\eta_{0}$ is return to scale.

Coelli (1996) has pointed out that "the output- and input-oriented models will estimate exactly the same frontier and therefore, by definition, identify the same set of DMU's as being efficient. It is only the efficiency measures associated with the inefficient DMU's that may differ between the two methods."

\section{Data and Variables}

Data for this study were derived from the annual reports from the Tennessee Department of Health and surveys of hospital governance. After all the hospitals with missing input and output variables were deleted, this dataset covered 125 general community hospitals in Tennessee and contained hospital-level information on clinics and utilization, as well as financial and organizational information. We surveyed all general community hospitals in Tennessee to determine what governance model each one followed. This study is based on data from the fiscal years 2008 to 2012, and the unit of analysis 
is the hospital.

DEA permits flexibility in selecting input and output variables as well as results if technical efficiency scores prove to be consistent across various input and output variables. Human resources and capital are critical variables in the production of health care services in hospitals. This study selected two input variables in efficiency analysis: bed occupancy and FTE (full-time equivalent). This study also selected four output variables: procedures, outpatients, inpatients, and charity. Of the input variables, number of beds indicates hospital size. Hospitals with more beds should realize economies of scale more easily than hospitals with fewer beds. The number of FTEs is intended to reflect the volume and range of work undertaken by health care professionals in hospitals. Regarding the output variables, procedures refer to medical procedures involving an incision with instruments performed to repair damage or arrest disease in a living body. The number of procedures reflects the capacity of the hospital. Outpatient and inpatient numbers indicate an estimate of a hospital's outpatient and inpatient workloads. Charity care is the total amount of free health care provided to patients who cannot pay for their health care services. The level of charity care reflects a hospital's core competency in delivering health care. Also, it serves as proxy for caseload mix. Charity care is deflated using the Consumer Price Index (CPI) published by the U.S Department of Labor. The CPI was scaled to 100 in 2008.

Table 1 shows the means and standard deviation of input and output variables from 2008 to 2012. Overall, means and standard deviation of input variables were steady

Table1. Descriptive Statistics $(M=125)$

\begin{tabular}{|c|c|c|c|c|c|c|}
\hline & Procedures & Outpatients & Inpatients & Charity $(\$)$ & Bed & FTE \\
\hline 2008 & $\begin{array}{c}22,420 \\
(27,678)^{*}\end{array}$ & $\begin{array}{c}73,372 \\
(90,184)\end{array}$ & $\begin{array}{c}28,648 \\
(36,134)\end{array}$ & $\begin{array}{c}2,079,214 \\
(7,414,119)\end{array}$ & $\begin{array}{c}164 \\
(168)\end{array}$ & $\begin{array}{c}628 \\
(873)\end{array}$ \\
\hline 2009 & $\begin{array}{c}24,920 \\
(29,197)\end{array}$ & $\begin{array}{c}68,693 \\
(85,916)\end{array}$ & $\begin{array}{c}30,275 \\
(38,270)\end{array}$ & $\begin{array}{c}2,555,900 \\
(10,170,053)\end{array}$ & $\begin{array}{c}163 \\
(166)\end{array}$ & $\begin{array}{c}639 \\
(888)\end{array}$ \\
\hline 2010 & $\begin{array}{c}29,841 \\
(40,813)\end{array}$ & $\begin{array}{c}72,080 \\
(95,018)\end{array}$ & $\begin{array}{c}30,511 \\
(38,894)\end{array}$ & $\begin{array}{c}3,291,362 \\
(12,401,480)\end{array}$ & $\begin{array}{c}163 \\
(166)\end{array}$ & $\begin{array}{l}639 \\
(915)\end{array}$ \\
\hline 2011 & $\begin{array}{c}27,739 \\
(33,711)\end{array}$ & $\begin{array}{c}73,778 \\
(102,378)\end{array}$ & $\begin{array}{c}31,628 \\
(41,796)\end{array}$ & $\begin{array}{c}4,171,697 \\
(16,980,877)\end{array}$ & $\begin{array}{c}161 \\
(166)\end{array}$ & $\begin{array}{l}639 \\
(940)\end{array}$ \\
\hline 2012 & $\begin{array}{c}29,129 \\
(34,992)\end{array}$ & $\begin{array}{c}74,031 \\
(108,668)\end{array}$ & $\begin{array}{c}30,585 \\
(39,892)\end{array}$ & $\begin{array}{c}6,807,091 \\
(21,530,019)\end{array}$ & $\begin{array}{c}163 \\
(167)\end{array}$ & $\begin{array}{l}637 \\
(986)\end{array}$ \\
\hline 2008-2012 & $\begin{array}{c}26,810 \\
(33,688)\end{array}$ & $\begin{array}{c}72,391 \\
(96,755)\end{array}$ & $\begin{array}{c}30,295 \\
(39,040)\end{array}$ & $\begin{array}{c}3,781,053 \\
(14,672,439)\end{array}$ & $\begin{array}{c}163 \\
(167)\end{array}$ & $\begin{array}{l}636 \\
(921)\end{array}$ \\
\hline
\end{tabular}

* standard deviation. 
during the period. Output variables increased steadily during this period. Standard deviations of output variables followed a similar pattern. That is, community hospitals in Tennessee treated more patients on average during this period.

\section{FINDINGS}

Table 2 reports annual technical efficiency estimates from 2008 to 2102 of the 125 Tennessee community hospitals in our study. Overall technical efficiency is the ability of an organization to convert multiple input variables into output variables. A hospital is considered to be technically inefficient if it operates below the production possibility frontier. Input/output configuration as well as the size of operations makes it possible to use the measurement of overall technical efficiency to determine inefficiency. Scale efficiency and pure technical efficiency can be adduced via the decomposition of the overall technical efficiency and are mutually exclusive and nonadditive components. This decomposition provides insight into the sources of inefficiencies. Pure technical efficiency, which estimates the efficient frontier under the assumption of a VRS scenario, reflects managerial performance in providing health care services and so is used as an index to capture managerial performance. Scale efficiency is the ratio of overall technical efficiency to pure technical efficiency. Scale efficiency reflects the ability of management to select the optimum amount of resources or to choose the scale of production that will achieve the expected production level. A hospital's being too small or too large may be a cause of technical efficiency.

Scale efficiency takes two forms: decreasing return to scale and increasing return to scale. Increasing return to scale means the hospital is too small for its scale of operations,

Table 2. All models $(M=125)$

\begin{tabular}{l|c|c|c}
\hline & INCRS & INVRS & INSCL \\
\hline 2008 & 0.519 & 0.666 & 0.795 \\
\hline 2009 & 0.407 & 0.599 & 0.717 \\
\hline 2010 & 0.490 & 0.623 & 0.794 \\
\hline 2011 & 0.343 & 0.612 & 0.592 \\
\hline 2012 & 0.579 & 0.689 & 0.844 \\
\hline $2008-2012$ & 0.468 & 0.638 & 0.748 \\
\hline
\end{tabular}

INCRS: technical efficiency from CRS DEA

INVRS: technical efficiency from VRS DEA

INSCL: scale efficiency = INCRS/INVRS 
while decreasing return-to-scale means that the hospital is too large to take full advantages of scale and has a supraoptimum scale size. When a hospital operates at constant return to scale, a hospital is scale efficient. Pure technical efficiency, recorded in table 2 , is the primary source of inefficiency in Tennessee community hospitals. The average overall technical efficiency was $46.5 \%$ for the 2008-2012 time period, while the averages of pure technical efficiency and scale efficiency were $63.8 \%$ and $74.8 \%$, respectively, for the same period. Scale efficiency enables management to choose the optimum size of input variables in order to determine the scale of production that will result in the expected production level.

Hospital governance, the process of steering the overall function and effective performance of a hospital by defining the hospital's mission, setting its objectives, and supporting and monitoring their realization at the operational level (Flynn, 2002), is considered to influence hospital performance, but there is no consensus exactly what its effects are. Still, it would be safe to say that in order to survive in a rapidly changing health care environment, hospitals need to understand the characteristics of an effective governing board and incorporate strategies to strengthen performance. The main purpose of this study is to explore the relationship between the types of governing boards and hospital performance. Studies that demonstrate the relationship between the characteristics of governing boards and hospital performance are beneficial to health care stakeholders, such as health care managers, public policy makers, patients, and creditors.

In order to measure the effects of governance on the performance of the $125 \mathrm{com}$ munity hospitals in Tennessee we surveyed, we draw on Alexander et al.'s (1988) and Weiner and Alexander's (1993) classification of hospitals governing boards as either philanthropic or corporate in nature. Some studies (Alexander et al., 1988, Pfeffer, 1973; Johnson, 1986; Kovner, 1978; Rehm \& Alexander, 1986; Alexander \& Lee, 2006) found that hospitals that operated according to a corporate governance model were more financially efficient than hospitals that operated according to a philanthropic model. Tables 3 and 4 report the performance of corporate governance hospitals and philanthropic governance hospitals among community hospitals in Tennessee.

This study found that the average overall technical performance was higher for hospitals that follow a corporate governance model than for hospitals that follow a philanthropic governance model; our results indicate that the average overall technical efficiency of hospitals that adopt a corporate governance model in Tennessee was about $8.8 \%$ higher than that of their counterparts. The average of pure technical efficiency is $76.0 \%$ in philanthropic governance hospitals and $75.4 \%$ in corporate governance hospitals, while the average of scale efficiency in philanthropic governance hospitals and corporate governance hospitals is $79.8 \%$ and $82.2 \%$, respectively, for the 2008-2012 period. 
Table 3. Philanthropic Governance Model $(\mathrm{M}=54)$

\begin{tabular}{l|c|c|c}
\hline & INCRS & INVRS & INSCL \\
\hline 2008 & 0.532 & 0.666 & 0.806 \\
\hline 2009 & 0.449 & 0.611 & 0.756 \\
\hline 2010 & 0.513 & 0.669 & 0.775 \\
\hline 2011 & 0.571 & 0.704 & 0.819 \\
\hline 2012 & 0.584 & 0.701 & 0.834 \\
\hline $2008-2012$ & 0.530 & 0.760 & 0.798 \\
\hline
\end{tabular}

Table 4. Corporate Governance Model $(\mathrm{M}=54)$

\begin{tabular}{l|c|c|c}
\hline & INCRS & INVRS & INSCL \\
\hline 2008 & 0.504 & 0.661 & 0.771 \\
\hline 2009 & 0.692 & 0.840 & 0.826 \\
\hline 2010 & 0.667 & 0.802 & 0.836 \\
\hline 2011 & 0.547 & 0.686 & 0.806 \\
\hline 2012 & 0.679 & 0.782 & 0.870 \\
\hline $2008-2012$ & 0.618 & 0.754 & 0.822 \\
\hline
\end{tabular}

\section{CONCLUSIONS AND POLICY IMPLICATIONS}

Hospitals are a critical part of health care delivery in the United States. In 2016, 4,926 community hospitals filled 786,874 hospital beds and admitted 33,066,720 patients (AHA, 2016). More than 1 in 10 who came through the emergency room were admitted to a hospital. Also, hospitals represent one of the largest employers in the community. Health care spending for hospitals was more than $\$ 970$ billion in 2014 (CMS, 2016). Despite this stature and strength, the hospital industry confronts massive and disruptive change. One out of three hospitals will close or merge with another health care provider by 2020 (Houle \& Fleece, 2012).

The Patient Protection and Affordable Care Act and the Health Care and Education Reconciliation Act of 2010 (ACA) strives to improve health care quality and reduce health care costs in the United States by encouraging hospitals, physicians, and other health care providers to charge patients through an integrated delivery system. The changes wrought by the ACA have given hospitals an opportunity to compete more 
strongly against other health care providers in improving health care quality and lessening duplication of health care services and unnecessary administrative costs. With increasing competition among health care providers, it is critical to understand the features of hospital governing boards; they are a core component in hospital governance, since they have a legal responsibility for establishing goals and objectives and supervising management performance.

Previous studies of the relationship between hospital governance and hospital performance have focused on a single aspect such as financial performance, responsiveness, equity, outcomes, and accessibility. In using DEA, this study has tried to take a more comprehensive view. Hospitals serve multiple functions. They diagnose and treat the sick and injured, prevent illness, and promote health. They educate health care professionals who will work in the health services community and conduct research with clinical trials for new drugs and devices as well as nonclinical research on such matters as how to enhance hospital processes though quality improvement. In taking these multiple functions into account, this study found that hospitals that follow a corporate governance model are more efficient than hospitals that follow a philanthropic governance model.

This study has focused on the importance of hospital governing boards by ascertaining which types of governing boards influence hospital performance in Tennessee. In exploring the relationship between hospital governance and performance, this study offers a more comprehensive measurement of health care governance and quality of management than that previous studies. To understand the dynamics of hospital governance, further studies using qualitative research methods need to conducted.

\section{REFERENCES}

Ali, A. L., \& Seiford, L. M. 1993. The mathematical programming approach to efficiency analysis. In H. Fried \& S. Schmidt (eds.), The measurement of productive efficiency: Techniques and applications (pp. 120-159). Oxford: Oxford University Press.

Alexander, J. A., Morlock, L. L., \& Gifford, B. D. 1988. The effects of corporate restructuring on hospital policymaking. Health Services Research, 23(2): 311-337.

Alexander, J. A., \& Lee, S.-Y. D. 2006. Does governance matter? Board configuration and performance in not-for-profit hospitals. Milbank Quarterly, 84(4): 733-758.

Alexander, J. A., Zuckerman, H. S., \& Pointer, D. D. 1995. The challenges of governing integrated health care systems. Health Care Management Review, 20(4): 69-81.

American Hospital Association. 2016. Fast facts on US hospitals. Retrieved on April 4, 2015, from www.aha.org/research/rc/stat-studies/fast-facts.shtml. 
Bader, B. S. 1991. Five keys to building an excellent governing board. Rockville, MO: Bader and Associates.

Banker R. D., Charnes A., \& Cooper W. W. 1984. Some models for the estimation of technical and scale inefficiencies in data envelopment analysis. Management Science, 30(9): 1078- 92.

Bevir, M. 2013. Governance: A very short introduction. Oxford: Oxford University Press.

Brickley, J. A., Coles, J. L., \& Jarrell, G. 1997. Leadership structure: Separating the CEO and chairman of the board. Journal of Corporate Finance, 3(3): 189-220.

Büchner, V. A. 2012. The impact of board characteristics on hospital performance. ECHE Conference, Zurich, Switzerland.

Burke, R. J. 1997. Women directors: Selection, acceptance and benefits of board membership. Corporate Governance, 5(3): 118-125.

Carter, D. A., Simkins, B. J., \& Simpson, W. G. 2003. Corporate governance, board diversity, and firm value. Financial Review, 38(1): 33-53.

Carver, J. 1990. Governing boards cost money too. Non-profit Times, 4(3): 31, 37-38.

Center for Medicare and Medicaid Services. 2015. National Health Expenditures 2014 Highlights. National Health Expenditures Data. Retrieved on April 4, 2016, from www.cms.gov/Research-Statistics-Data-and-Systems/Statistics-Trends -and-Reports/NationalHealthExpendData/index.html.

Chait, R., Ryan, W., \& Taylor, B. 1996. Governance as leadership: Reframing the work of nonprofit boards. Phoenix, AZ: Oryx Press.

Charan, R. 2005. Boards that deliver: Advancing corporate governance from compliance to competitive advantages. San Francisco: Jossey-Bass.

Charnes A., Cooper W. W., \& Rhodes E. 1978. Measuring the efficiency of decisionmaking units. European Journal of Operational Research, 2(6): 429-444.

Charnes, A., Cooper, W. W., Lewin, A. Y., \& Seiford, L. M. 1995. Data Envelopment Analysis: Theory, methodology, and applications. Boston: Kluwer, 1995.

Coelli, T. 1996. A guide to DEAP Version 2.1: A data envelopment analysis. CEPA working paper 96/08. Armidale, NSW: University of New England, 1996.

Coelli T. 1998. A multi-stage methodology for the solution of orientated DEA models. Operations Research Letters, 23(3-5): 143-149.

Conger, J. A., Lawler, E. E., III, \& Finegold, D. L. 2001. Corporate boards: New strategies for adding value at the top. San Francisco: Jossey-Bass.

Delbecq, A. L., \& Gill, S. L. 1988. Developing strategic direction for governing boards. Hospital and Health Services Administration, 33(1): 25-35.

Eeckloo, K., Van Herck, G., Van Hulle, C., \& Vleugels, A. 2004. From corporate 
governance to hospital governance: Authority, transparency and accountability of Belgian non-profit hospitals' board and management. Health Policy, 68(1): $1-15$.

Ewell, C. 1987. The governance challenge: Integrating multiple levels. Healthcare Executive, 2(2): 14-17.

Fama, E. F., \& Jensen, M. 1983. Separation of ownership and control. Journal of Law and Economics, 26(2): 301-325.

Farrell M. J. 1957. The measurement of productive efficiency. Journal of the Royal Statistical Society, series A (general), 20(3): 253-290.

Ferrer, G., Rosko, M., \& Valmanis, V. 2006. Analysis of uncompensated hospital care using a DEA model of output congestion. Health Care Management Science, 9(2): 181-188.

Flynn, R. 2002. Clinical governance and governmentality. Health, Risk and Society, 4(2): 155-173.

Goes, J. B., \& Zhan, C. 1995. The effects of hospital-physician integration strategies on hospital financial performance. Health Services Research, 30(4): 507-521.

Gu, Y., Langabeer, J. R., \& Helton, J. R. 2010. Board composition and financial performance in major hospitals. International Journal of Corporate Governance, 2(1): 21-30.

Hollingsworth, B., \& Parkin, D. 1995. The efficiency of Scottish acute hospitals: An application of data environment analysis. Mathematical Medicine and Biology, 12(3-4): 161-173.

Houle, D., \& Fleece, J. 2012. Why one-third of hospitals will close by 2020. KevinMD. com, March 14. Retrieved on April 4, 2016, from: www.kevinmd.com/blog/ 2012/03/onethird-hospitals-close-2020.html.

Jensen, M. C. 1993. The modern industrial Revolution, exit, and the failure of internal control systems. Journal of Finance, 48(3): 831-880.

Jermias, J. 2007. The effects of corporate governance on the relationship between innovative efforts and performance. European Accounting Review, 16(4): 827-854.

Johnson, T. 1986. Improving board effectiveness in hospitals: Can the corporate model help? Working paper, University of Pennsylvania, Philadelphia.

Kim, J. 2007. Nongovernmental organizational governance and corporate governance: A comparative analysis. Korean Journal of Policy Studies, 22(1): 47-71.

Kovner, A. 1978. Improving community hospital board performance. Medical Care, 16(1): 79-89.

Kovner, A. 1990. Improving hospital board effectiveness: An update. Frontiers of Health Services Management, 6(3): 4-26. 
Linna, M., Häkkinen, U., \& Magnussen, J. 2006. Comparing hospital cost efficiency between Norway and Finland. Health Policy, 77(3): 268-278.

Lipton, M., \& Lorsch, J. W. 1992. A modest proposal for improved corporate governance. Business Lawyer, 48(1): 59-77.

Lovell, C. A. K. 1993. Production frontiers and productive efficiency. In H. Fried \& S. Schmidt (eds.), The measurement of productive efficiency: Techniques and applications (pp.). Oxford: Oxford University Press.

Mace, M. 1976. Designing a plan for the ideal board. Harvard Business Review, 54(6): 20-29.

Molinari, C., Morlock, L., Alexander, J. A., \& Lyles, C.A. 1993. Hospital board effectiveness: Relationships between governing board characteristics and hospital financial viability. Health Services Research, 28(3): 357-370.

Pfeffer, J. 1973. Size, composition, and function of hospital boards of directors: A study of organizational-environment linkage. Administrative Science Quarterly, 18(2): 349-64.

Pound, J. 1995. The promise of the governed corporation, Harvard Business Review, 73(2): 89-98.

Prybil, L. D. 2006. Size, composition, and culture of high-performing hospital boards, American Journal of Medical Quality, 21(4): 224-229.

Rehm, J., \& Alexander, J. 1986. Governing board compensation revisited. Trustee, 39(4): 24-27.

Roh, C., Moon, J., \& Jung, K. 2013. Efficiency disparities among community hospitals in Tennessee: Do size, location, ownership, and network matter? Journal of Health Care for the Poor and Underserved, 24(4): 1816-1833.

Sanders, W. G., \& Carpenter, M. A. 1998. Internationalization and firm governance: The roles of CEO compensation, top team composition and board structure. Academy of Management Journal, 40(2): 158-178.

Seiford, L. M., \& Thrall, R. M. 1990. Recent developments in DEA: The mathematical programming approach to frontier analysis. Journal of Econometrics, 46(1-2): 7-38.

Shortell, S., \& LoGerfo, J. 1981. Hospital medical staff organization and quality of care. Medical Care, 19(10): 1041-1055.

Singh, V., Vinnicombe, S., \& Johnson, P. 2001. Women directors on top UK boards. Corporate Governance, 9(3): 206-216.

Taylor, W. D. 2000. Facts, myths and monsters: Understanding the principles of good governance. The International Journal of Public Sector Management, 13(2): 108-124. 
Weiner, B. J., \& Alexander, J. A. 1993. Corporate and philanthropic models of hospital governance: A taxonomic evaluation. Health Services Research, 28(3): 325-255.

Young, G., Beekun, R. I., \& Ginn, G. O. 1992. Governing board structure, business strategy, and performance of acute care hospitals: A contingency perspective. Health Services Research, 27(4): 543-564. 